\section{HUMAN BLOOD GROUPS}

\author{
By J. F. LOUTIT
}

$\mathrm{T}$ HE blood group of a person is dependent upon the presence in his erythrocytes of specific antigens. These antigens, most easily demonstrated by agglutination methods, are usually referred to as 'agglutinogens'. The corresponding antibodies, or agglutinins, may or may not be found naturally in human sera. If not found naturally, they may be produced by an immune response in suitable human or animal subjects after the injection of erythrocytes containing the appropriate antigen.

Academically, the blood groups are of importance in the elucidation of the antigenic structure of tissue cells. Application of this knowledge to blood transfusion therapy, to medico-legal problems concerning disputed paternity, blood stains, etc., and to anthropological and genetic research follows.

First, there is a genus specificity of blood. Thus the serum of human beings will agglutinate the erythrocytes of lower animals; likewise the serum of each genus of animal will agglutinate human erythrocytes and those of other animal genera.

Secondly, there is frequently a difference between the bloods of individuals belonging to the same species. Landsteiner ${ }^{1}$ first demonstrated this in human beings. Our knowledge of human blood groups dates from this original observation.

Landsteiner and his pupils were able to divide human beings into four groups, the groups being dependent upon the presence in the red cells of either or both of two iso-agglutinogens $A$ and $B$, or their absence. An international nomenclature has been adopted on this antigenio basis, and the groups are now designated $A B, A, B$ and $O(O$ signifying absence of both $A$ and $B$ ). Naturally-occurring iso-agglutinins $\alpha$ (anti $-A$ ) and $\beta$ (anti- $B$ ) are found in the sera according to Landsteiner's law : Those agglutinins, and only those, are present in the serum for which there is no corresponding agglutinogen in the red blood cells. The groups are thus $A B(o), A(\beta), B(\alpha)$ and $O(\alpha \beta)$. Occasionally, however, defective groups are found, for example, $A(o)$ or $O(\alpha)$. This is rare in adults, but not uncommon in infants.

Subdivision of two of the blood groups, $A$ and $A B$, was made by von Dungern and Hirzfeld ${ }^{2}$ in 1911 . Serum from a group $B$ person, absorbed with certain group $A$ bloods, lost its power of agglutinating other samples of these bloods, but still agghtinated most other bloods of group $A$. This phenomenon is apparently due to the presence of two iso-agglutinins in group $B$ sera (and group $O$ sera), $\alpha$ which agglutinates all group $A$ and $A B$ erythrocytes, and $\alpha_{1}$ which agglutinates most but not all $A$ and $A B$ red cells. The bloods agglutinated by $\alpha_{1}$ are designated $A_{1}$ and $A_{1} B$ : those agglutinated only by $\alpha$ are $A_{2}$ and $A_{2} B$. It has been suggested that the difference between $A_{t}$ and $A_{2}$ (and $A_{1} B$ and $A_{2} B$ ) is merely quantitative. On the other hand, there is evidence of a qualitative difference in that individuals of groups $A_{2}$ and $A_{2} B$ can be immunized against $A_{1}$ blood by repeated transfusions, or, in the case of women, by bearing a child whose blood contains the antigen $A_{1}$ (Wiener ${ }^{3}$ ). Group $A$ bloods which react with the iso-agglutinin even more weakly than $A_{2}$ cells have been deseribed and denoted as $A_{3}{ }^{4}$ and $A_{4}{ }^{5}$. Sub-groups of the $B$ agglutinogen have not been discovered. The isoagglutinin $\alpha_{1}$ can oceur naturally in the sera of individuals of group $A_{2}$ and $A_{2} B$ as well as those of group $O$ and $B$. In the former cases it is usually active only in the cold below $37^{\circ} \mathrm{C}$.

The agglutinogens $A$ and $B$ are inherited as mendelian dominants. Von Dungern and Hirzfeld ${ }^{6}$, who first proved this, considered that the inheritance depended upon two independent pairs of allelomorphic genes. Bernstein? showed that this hypothesis did not fit the statistical findings, and suggested that inheritance depended upon three allelomorphic genes, $A, B$ and $R$ (or $O$ ). This theory is now generally accepted, with the rider that $A_{1}, A_{2}, A_{3}$ and $A_{*}$ form a series of allelomorphic genes which determine the $A$ antigen.

Under von Dungern and Hirzfeld's theory, group $O$ individuals would merely possess erythrocytes lacking $A$ and $B$ agglutinogens. With Bernstein's theory it might be expected that such cells would contain an agglutinogen " $O$ ". In point of fact, a water-soluble group-specific substance has been prepared from $O$ cells (Hallauer ${ }^{8}$ ). Moreover, sera which will selectively agglutinate $O$ cells are known (Schiff $\left.{ }^{\circ}\right)$. These anti-O sera are often designated as $\alpha_{2}$ sera as they also agglutinate the majority of $A_{2}$ bloods, probably those of the heterozygous $\mathrm{A}_{2} \mathrm{O}$ genotype. They occur in some natural animal sera (Schiff ${ }^{\circ}$ ), for example, bovine, some immune sera (Hooker and Anderson ${ }^{10}$ ) and as cold iso-agglutinins (Landsteiner and Levine ${ }^{11}$ ) in some group $B, A_{1}$ or $A_{1} B$ human sera.

Agglutinable factors in human red cells, other than the agglutinogens $A$ and $B$, have also been discovered. From certain immune rabbit sera, Landsteiner and Levine ${ }^{12}$ obtained agglutinins for two factors which they called $M$ and $N$. Human red cells can contain either or both of these agglutinogens (but not neither). Iso-agglutinins in human serum for $M$ have been reported only in a very few instances, but no reliable report of an iso-agglutinin for $N$ has appeared.

Friedenreich ${ }^{13}$ has described a rare sub-group of $N$ which has been termed $N_{2}$.

The $M$ and $N$ factors, as shown by Landsteiner and Levine ${ }^{14}$, are inherited as mendelian dominants and their heredity depends upon a single pair of allelomorphic genes.

Other agglutinogens have also been reported from time to time. Of these the best-known is the factor $P$, which like the $A$ substance probably represents a group of related agglutinogens ${ }^{15}$. The antibody can be obtained from normal and immune animal sera and occasionally in human sera (extra-agglutinin-1).

The group specific substances $A$ and $B$ have frequently been demonstrated in tissues other than erythrocytes (cf. Landsteiner and Levine ${ }^{17}$ ) by specific absorption and inhibition techniques. Schiff ${ }^{18}$ extracted these substances in two forms, water-soluble and alcoholsoluble. Schiff ${ }^{19}$ also found them in body fluids of certain subjects. Schiff and Sasaki ${ }^{20}$ have called such people 'secretors' : they have also found group $O$ 'secretors'. The power of secretion is inherited as a mendelian dominant.

The $M$ and $N$ substances were for a long time thought to be confined to erythrocytes. They have lately been found in normal tissues by Kosjakov and Tribulev ${ }^{21}$ and Boorman and IDodd ${ }^{22}$, who also showed that the $R h$ substance (vide infra) was present in tissues. It would appear that $M, N$ and $R h$ are relatively insoluble in water, as their presence in saliva is minimal.

The group specific antigens are, like other antigens, protein in nature. Haptenes derived from commercial pepsin, peptone, etc., however, have been 
prepared which possess to a high degree the serological characteristics of the blood group $A$ factor (Schiff and Weiler ${ }^{23}$ ) and the group $B$ factor (Witebsky and Klendshoj ${ }^{24}$ ) without being themselves antigenic. They are polysaccharide complexes without protein. An artificial antigen of group $A$ specificity has been prepared (Morgan ${ }^{25}$ ) by combining the $A$ hapten with a protein.

Historically the latest and, from the transfusion therapy viewpoint, after $A$ and $B$ the most important blood group factor to be described, is $R h$. It was first demonstrated (Landsteiner and Wiener ${ }^{26}$ ) by the use of an immune agglutinin produced in rabbits by injection of the blood of rhesus monkeys. The identity of this agglutinin with immune iso-agglutinins produced in man by repeated transfusions of blood of the correct $A B O$ group ${ }^{22}$ or by pregnancy ${ }^{28,29}$ was soon demonstrated. In both instances persons whose erythrocytes lacked the $R h$ factor had been immunized by the $R h$ antigen. In the transfusion cases the blood transfused contained the $R h$ antigen in the erythrocytes; in the pregnancy cases it is necessary to postulate a leak of $R h$ antigen across the placental barrier from foetus to mother.

In pregnancy, Levine, Katzin and Burnham ${ }^{28}$ showed that this iso-immunization of the mother reflected on the newborn child, which manifested signs of 'erythroblastosis fœtalis' (hydrops fotalis, icterus gravis neonatorum, congenital anæmia of the mewborn). In view of the now accepted etiology of this condition, hæmolytic disease of the newborn is a preferable term. The immune iso-agglutinin passes back across the placenta and interacts with the foetal erythrocytes and destroys them. Ottenberg ${ }^{30}$ had previously suggested that this disease could be caused by iso-agglutinins $\alpha$ or $\beta$ of the mother affecting her fotus of group $A$ or $B$ respectively. The $A B O$ blood groups, however, had no relation to the disease, and it is thought that the water-soluble group specific substances present in the body fluids of most $A$ and $B$ fotuses would neutralize the offending agglutinin. Non-secretors would, on the other hand, be liable to be affected, and a few cases of hæmolytic disease of the newborn may be due to this cause. Immune iso-agglutinins, other than the typical $R h$, could also produce it.

Suitable antibodies for the detection of the $R h$ factor are available by animal immunization-rabbit (Landsteiner and Wiener ${ }^{26}$ ) and guinea pig (Landsteiner and Wiener ${ }^{31}$ )-or they can be obtained from immunized human subjects. A special technique for their detection is required ${ }^{32,33}$. Different sera do not always give absolutely identical results, so for each $\boldsymbol{R} h$ determination at least three sera should be used. In these circumstances it is found in the white popula. tions of London ${ }^{33}$ and New York ${ }^{34}$ that approximately 85 per cent of persons are $R h$ positive and 15 per cent $\boldsymbol{R} \boldsymbol{h}$ negative.

It should be noted that, whereas 92 per cent of 153 mothers of infants with hæmolytic disease of the newborn were $R h$ negative (Levine, Burnham, Katzin and Vogel $^{35}$ ), not all $R h$ negative mothers with $R h$ positive husbands (12 per cent of all matings) have affected infants. The $R h$ factor is inherited as a mendelian dominant (Landsteiner and Wiener ${ }^{32}$ ). If the father is heterozygous, $R h r h$, half the offspring will be $R h$ negative and therefore unaffected. Even if the father be homozygous $R h R h$, although all the offspring will be $R h$ positive, one or more of the first children may be spared, because a greater degree of iso-immunizing stimulus may be necessary than is provided or the mother may be unduly resistant. In fact, it has been calculated (Javert ${ }^{36}$ ) that only 1 of every 438 new. born infants suffers from one or other form of the disease.

On the other hand, while 90 per cent approximately of mothers of infants with hæmolytic disease are $R h$ neg itive, the remzinder are $R h$ positive. These subjects, like the $R h$ negative cases, show evidence of iso-immunization by their foetus and provide interesting antibodies. One such antibody described by Levine, Javert and $\mathrm{Katzin}^{37}$ and designated anti-Hr reacted mainly with $R h$ negative bloods, but also with some $R h$ positive bloods. A somewhat similar antibody has been denoted by Race and Taylor ${ }^{38}$ as $S t$. It agglutinated all $R h$ negative bloods and all heterozygous ( $R h r h$ ) bloods, but failed to agglutinate about 20 per cent of all bloods, and these must therefore be homozygous RhRh. Race, Taylor, Boorman and Dodd ${ }^{39}$ report yet another antibody $(K J)$ which reacted with approximately 30 per cent of all bloods. This is similar to an antibody just reported by Wiener ${ }^{40}$. Race et al. suggest from the reactions of the $R h, S t$ and $K J$ antibodies the probability of there being at least five allelomorphic genes: $R h_{1}$, $R h_{2}, R h_{x}, R h_{y}$ and $r h$.

It will be remembered that not all anti- $R h$ sera give identical results. 84-85 per cent of positive reactions were obtained with standard animal serum (Landsteiner and Wiener ${ }^{26}$ ); 70 per cent with a human serum described by Wiener ${ }^{28}$ and $86-87$ per cent with most human sera (Levine et al. ${ }^{25}$ ). Wiener now calls the standard animal serum anti-Rh, the 70 percenter anti- $R h_{1}$ and the 87 percenter anti- $R h^{\prime}$. This anti- $R h^{\prime}$ is really a mixture of the two agglutinins anti-Rh and anti-Rh $h_{1}$ and, by absorption with $R h$ positive bloods which do not react with anti- $R h_{1}$ serum, the anti- $R h_{1}$ agglutinin can be isolated. It was postulated (Wiener and Landsteiner ${ }^{41}$ ) that bloods which reacted with this anti- $R h_{1}$ agglutinin belonged to type $R h_{1}$, and those that reacted only with the standard guinea pig serum to type $R h_{2}$. Up to this point, types $R h_{1}$ and $R h_{2}$ were analogous to group $A_{1}$ and $A_{2}$ bloods. Some rare bloods (Landsteiner and Wiener ${ }^{32}$ ), however, react with anti- $R h_{1}$ (and therefore anti- $R h^{\prime}$ ) but' not with standard animal anti-Rh. The agglutinin, recently described by Wiener ${ }^{40}$, reacting with 30-35 per cent of normal bloods, agglutinates bloods of, so-called type $R h_{2}$.

I have had the privilege of seeing a personal communication from Wiener, the manuscript of a paper to be published. The reactions of bloods to the agglutinins anti- $R h$, anti- $R h_{1}$, anti- $R h_{2}$ and anti- $R h^{\prime}$ are explained by postulating six allelic genes $R h_{1}, R h_{2}$, $R h, R h^{\prime}, R h^{\prime \prime}$ and $r h$. $R h^{\prime \prime}$ appears to be identical with the $R h_{x}$ of Race et al., but $R h^{\prime}$ appears to differ from $R h_{\nu}$.

Race, Taylor, Cappell and McFarlane ${ }^{42}$, by using an anti- $R h_{1}$ serum in addition to anti- $R h, S t$ and $K J$ sera, have confirmed the existence of the rare genes $R h^{\prime}$ and $R h$ of Wiener, but suggest that the latter be termed $R h_{0}$ as $R h$ has for so lang had a wider meaning. The reactions of the various sera in identifying the genes can be best summarized as in the accompanying table.

By means of these four anti-sera, the genotypes of about 80 per cent of people can be determined if one ignores the rare genotypes. These latter can, however, often be detected by famfly studies.

The antibodies anti- $R h_{1}, K J$ (anti- $R h_{2}$ ), St and anti-Rh (animal) appear to be single antibodies and 


\begin{tabular}{|c|c|c|c|c|}
\hline \multirow{2}{*}{ Genes } & \multicolumn{4}{|c|}{ Anti-sera } \\
\hline & $R h$ & St & $\boldsymbol{K} J$ & $R h_{1}$ \\
\hline $\begin{array}{l}R h_{1} \\
R h_{2} \\
R h_{1} \\
R h^{\prime} \\
R h^{\prime \prime} \\
r h \\
R h_{y}\end{array}$ & $\begin{array}{l}+ \\
\pm \\
\pm \\
\frac{+}{?}\end{array}$ & $\begin{array}{l} \pm \\
+ \\
+ \\
+ \\
+\end{array}$ & $\begin{array}{l}\overrightarrow{ \pm} \\
\overrightarrow{ \pm} \\
\overrightarrow{+}\end{array}$ & $\frac{ \pm}{ \pm}+\frac{}{?}$ \\
\hline
\end{tabular}

\section{UNCONSIDERED TRIFLES IN OUR DIET}

\author{
VITAMIN CONTENT OF BEVERAGES
}

\section{By SIR J. C. DRUMMOND and $D_{R}$. T. MORAN}

T will be of interest to students of nutrition to 1 point out some of the important results that have been obtained during the past twelve months from a re-examination of the contribution made to the nutritive value of our diet by common foods that are often ignored when evaluations are being made.

One of us (T. M.), in collaboration with Dr. J. B. Hutchinson', pointed out that water drunk in one form or another can add substantially to the daily calcium intake. An approximate estimate of that provided by drinking-water alone over the country as a whole was $75 \mathrm{mgm}$. a day. In some areas where the water is 'hard', the figure would be much larger. A modest pint of beer daily can provide about $70 \mathrm{mgm}$. . Such quantities should not be ignored in calculating calcium intakes. Widdowson and $\mathrm{McCance}^{2}$ have also stressed the importance of calcium from such sources, and have shown that contact of food with iron utensils often materially raises the quantity of iron in the diet.

Consideration of beer led to a re-investigation of its vitamin content. Since the original study by Harden and Zilva 8,4 , it has been widely assumed that beers consumed in Great Britain have a vitamin content that is negligible. In the Medical Research Council Special Report on Vitamins ${ }^{5}$ published in 1932, there is, however, a reference to an unpublished observation by Aykroyd that stout contains what was then known as "vitamin $\mathrm{B}_{2}$ ", but no further information about this has been traced. In view of the properties of ribofldvin and nicotinic acid, as contrasted with those of $B_{1}$ which is readily adsorbed by yeast, it appeared reasonable to expect that beer would contain a high proportion of the amounts of these two substances contained in the malt. This has proved to be the case. Both in the laboratories of the Cereals Research Station of the Ministry of Food and in Prof. R. H. Hopkins's Department at the University of Birmingham, riboflavin values for beers ranging from 0.5 to $1 \cdot 7 \mu \mathrm{gm}$./c.c. have been found ${ }^{6,7}$

The riboflavin content of beer appears to be related to the strength of the brew. Samples of malt that we have examined have given values of $5 \cdot 6 \mu \mathrm{gm} . / \mathrm{gm}$. (as against $2.5 \mathrm{\mu gm}$./gm. for barley), and on the basis of one pound of barley yielding three and a half pints of beer (corresponding roughly to present-day beer) it would follow that complete extraction of the riboflavin from the malt would give a beer of approximately $1 \cdot 3 \mu \mathrm{gm}$./c.c. Complete extraction is unlikely, but it indicates the limiting riboflavin content. On the other hand, a sample of strong ale as supplied to Queen's College, Oxford, before the War gave a riboflavin figure of $3.9 \mu \mathrm{gm}$./c.c. What promised to be an even more interesting ale-a brew of 1798 to celebrate the battle of the Nile, kindly supplied to us by Mr. Julian Baker-gave the disappointing figure of $0.8 \mu \mathrm{gm} . / \mathrm{c} . c$. Very probably there had been some destruction of the vitamin during the intervening 150 years.

In these examinations the riboflavin values were determined by the microbiological technique ${ }^{8}$, but a biological test on a sample of beer sent to Miss Copping 